\title{
Synthesis and characterization of $\mathrm{BaTiO}_{3} / \alpha-\mathrm{Fe}_{2} \mathrm{O}_{3}$ core/shell structure
}

\author{
Suzana FILIPOVIĆ ${ }^{a, *}$, Vera P. PAVLOVIĆ ${ }^{b}$, Miodrag MITRIĆc, \\ Steva LEVIĆ ${ }^{d}$, Nebojša MITROVIĆ ${ }^{e}$, Aleksa MARIČIĆ ${ }^{e}$, \\ Branislav VLAHOVIĆ ${ }^{f, g}$, Vladimir B. PAVLOVIĆ ${ }^{a}$ \\ ${ }^{a}$ Institute of Technical Sciences of Serbian Academy of Sciences and Arts, \\ Knez Mihailova 35/IV, 11000 Belgrade, Serbia \\ ${ }^{b}$ Faculty of Mechanical Engineering, University of Belgrade, Kraljice \\ Marije 16, 11000 Belgrade, Serbia \\ c "Vinča” Institute of Nuclear Sciences, University of Belgrade, Mike Petrovića Alasa \\ 12-14, 11000 Belgrade, Serbia \\ ${ }^{d}$ Faculty of Agriculture, University of Belgrade, Nemanjina 6, 11080 Zemun, Belgrade, Serbia \\ ${ }^{e}$ Faculty of Technical Sciences Čačak, University of Kragujevac, Svetog Save 65, 32000 Čačak, Serbia \\ ${ }^{f}$ North Carolina Central University, Durham, NC, USA \\ ${ }^{g}$ NASA University Research Center for Aerospace Device Research and Education and NSF \\ Center of Research Excellence in Science and Technology Computational Center for Fundamental and \\ Applied Science and Education, NC, USA
}

Received: July 17, 2018; Revised: October 3, 2018; Accepted: October 22, 2018

(C) The Author(s) 2019.

\begin{abstract}
Multiferroic materials attracted a lot of attention in recent years because of their significant scientific interest and technological applications. The multiferroic core/shell powders have a better connectivity between the phases, resulting in superior dielectric and magneto electric properties. In this study, the influence of preparation condition on structure and properties of $\mathrm{BaTiO}_{3} / \alpha-\mathrm{Fe}_{2} \mathrm{O}_{3}$ core/shell composite materials was examined. The five samples were obtained by varying synthesis conditions, such as synthesized method (co-precipitation and sonochemical method) and $\mathrm{pH}$ values of solution. XRD and Raman spectroscopy analyses were performed in order to determine phase composition and structural changes within samples. Morphology modifications were examined by SEM and EDS analyses. Finally, effect of structural and microstructural changes on magnetic and electrical properties was detected and explained.
\end{abstract}

Keywords: ceramics; electronic materials; magnetic materials; Raman spectroscopy; X-ray diffraction (XRD); ferroelectricity

\section{Introduction}

Multiferroic materials, exhibiting more than one ferroic

* Corresponding author.

E-mail: suzana.filipovic@itn.sanu.ac.rs property (ferromagnetism, ferroelectricity, and ferroelasticity) have drawn a wide scientific and technological attention in the present years for the fundamental research and due to the variety of possible practical applications [1,2]. Among them, materials that exhibit both magnetism and ferroelectricity (often 
termed ferroelectromagnetic multiferroics) are especially important, because they can be used in various microelectronic devices, including microwave phase shifters, magnetically controlled electro-optic or piezoelectric devices, and broadband magnetic field sensors [3-5].

Up to now, various types of crystalline structures of single-phase ferroelectromagnetic multiferroics such as perovskites $\left(\mathrm{ABO}_{3}\right)$, bismuth layer perovskite-like oxides $\left(\mathrm{A}_{m-1} \mathrm{Bi}_{2} \mathrm{~B}_{m} \mathrm{O}_{3 m+3}\right)$, boracites $\left(\mathrm{Me}_{3} \mathrm{~B}_{7} \mathrm{O}_{13} \mathrm{X}\right), \mathrm{RMnO}_{3}$-type $(\mathrm{R}=\mathrm{Y}, \mathrm{Ho}, \mathrm{Er}, \mathrm{Yb}, \mathrm{Tu}, \mathrm{Lu}, \mathrm{Sc})$ hexagonal manganites, $\mathrm{BaMeF}_{4}$-type $(\mathrm{Me}=\mathrm{Mn}, \mathrm{Fe}, \mathrm{Co}, \mathrm{Ni})$ hexagonal fluorites, hexagonal $\mathrm{BaTiO}_{3}$-type compounds, tungstenbronze-type niobiate compounds (e.g., $\mathrm{Ba}_{6} \mathrm{Nb}_{9} \mathrm{FeO}_{30}$, $\mathrm{Sr}_{6} \mathrm{Nb}_{9} \mathrm{FeO}_{30}$ ), as well as other compounds and solid solutions (e.g., $\mathrm{FeS}, \mathrm{Cu}(\mathrm{HCOO})_{2} \cdot 4 \mathrm{H}_{2} \mathrm{O}, \mathrm{Li}\left(\mathrm{Fe}_{1 / 2} \mathrm{Ta}_{1 / 2}\right) \mathrm{O}_{2} \mathrm{~F}$ ) have been found [6-9]. However, single phase materials that exhibit a coupling of magnetism and ferroelectricity are relatively rare [10]. This is mainly attributed to the presence of transition metal $d$ electrons, which are essential for magnetism, but hinder the tendency for off-center structural distortions which are necessary for ferroelectricity [11]. Therefore, an alternative approach for engineering enhanced ferroelectromagnetic effects is to introduce indirect coupling, via strain, which arises from the interaction of ferroelectric and ferromagnetic phases of different materials. The mechanism of the interaction can be described by the induced deformation of the piezoelectric (electrostrictive) phase upon applying an external electric field that is transmitted to the magnetostrictive phase through the shared interface and causes a change in its magnetization (or vice versa). Strain coupling requires intimate contact between constituent phases and can be achieved for various types of composites including particulate bulk composites, core/shell structures, thin and thick films [1,2,12-15]. It was demonstrated that multiferroic core/shell structures have a better connectivity between the phases, resulting in superior dielectric and magnetoelectric properties [16].

Core/shell particles, in general, consist of a core as an interior material and a shell as an outer layer material. Both, core and shell could be made of different types of material inorganic or organic, so a large number of combinations are possible including inorganic/ inorganic, inorganic/organic, organic/inorganic as well as organic/organic. Up to now, by using combined hydrothermal and annealing processes [2], sol-gel method [17] and co-precipitation [18], a various shapes of core/shell particles (spherical core/shell particles; hexagonal core/shell particles; multiple small core materials coated by single shell material; nanomatryushka material, etc. [19]) were synthesized.

One of the most often used ferroelectric material for core/shell multiferroic structured composite is $\mathrm{BaTiO}_{3}$, due to its good chemical stability, high dielectric constant (around 4000-5000), and low loss in a wide frequency range $[20,21]$. Up to now, various core/ shell-type multiferroic $\mathrm{BaTiO}_{3} / \gamma-\mathrm{Fe}_{2} \mathrm{O}_{3}, \mathrm{BaTiO}_{3} / \mathrm{Fe}_{3} \mathrm{O}_{4}$, $\mathrm{CoFe}_{2} \mathrm{O}_{4} / \mathrm{BaTiO}_{3}, \quad \mathrm{Fe}_{3} \mathrm{O}_{4} / \mathrm{BaTiO}_{3}, \quad \mathrm{Fe}_{3} \mathrm{O}_{4} / \mathrm{Pb}(\mathrm{Zr}, \mathrm{Ti}) \mathrm{O}_{3}$, $\mathrm{CoFe}_{2} \mathrm{O}_{4} / \mathrm{BaTiO}_{3}$, in which $\mathrm{BaTiO}_{3}$ was used either as a core or as a shell were synthesized [2,14,22-25].

Since electrical properties and therefore applications of $\mathrm{BaTiO}_{3}$ based materials are sensitive to their microstructure, especially pore, grain size distribution, and grain boundary conditions, it is very important to understand the nature of these relations [26]. The problem of size-induced changes of the phase transition is of great importance, both from fundamental and application point of view. It is essential to know the temperature range of the stability of the ferroelectric phase in a volume with reduced spatial dimensions and the existence of a critical size for ferroelectric interaction, since they may be a technological limitation for miniaturization. It has been shown that the spontaneous polarization decreases with decreasing particle size and eventually disappears, that is, a size-driven phase transition takes place [27]. The ferroelectric critical size has been defined as the size at which the $\mathrm{BaTiO}_{3}$ ferroelectric tetragonal-paraelectric cubic phase transition takes place. Experimental results show that the critical crystallite size depends on the powder preparation method and in some cases goes up to $100 \mathrm{~nm}$. On the other hand, our investigation has shown that the applied mechanical activation can lead to the formation of nanocrystalline tetragonal structure, even for particles as small as $\sim 30 \mathrm{~nm}$ [28]. Taking all this into account and since, up to now, no systematic analysis of the synthesis and properties of $\mathrm{BaTiO}_{3} / \alpha-\mathrm{Fe}_{2} \mathrm{O}_{3}$ core/shell structured materials has been performed, in this article, our research focuses on the effects of preparation condition on structure and properties of this type of ceramics.

\section{Experimental}

As starting reagents in experiments, $\mathrm{Fe}\left(\mathrm{NO}_{3}\right)_{3} \cdot 9 \mathrm{H}_{2} \mathrm{O}$ (Sigma Aldrich), $\mathrm{BaTiO}_{3}$ (Sigma Aldrich), and $\mathrm{NaOH}$ 
(Sigma Aldrich) were used. All chemicals employed for the synthesis were analytically graded. Five samples, BTF1-BTF5, were synthesized. The detail description of synthesis process is given below.

BTF1 was synthesized by combination of coprecipitation and sonochemical method. Aqueous solution of $\mathrm{NaOH}(1 \mathrm{~mol} / \mathrm{L})$ was slowly added dropwise into the aqueous solution of $\mathrm{Fe}\left(\mathrm{NO}_{3}\right)_{3} \cdot 9 \mathrm{H}_{2} \mathrm{O}$ which had been kept on a magnetic stirrer for vigorous stirring. The procedure kept going until the $\mathrm{pH}$ value of 12 was reached. Stirring was continued for $1 \mathrm{~h}$. In addition, commercially $\mathrm{BaTiO}_{3}$ was dispersed into such prepared solution and suspension was ultrasonicated for another hour. The used weight ratio of $\mathrm{BaTiO}_{3} / \mathrm{Fe}\left(\mathrm{NO}_{3}\right)_{3} \cdot 9 \mathrm{H}_{2} \mathrm{O}$ was 1.2. Afterward, the yield was washed with distillate water and followed by drying in an oven at $60{ }^{\circ} \mathrm{C}$ over night. Obtained materials were pulverized in a mortar, and subsequently heated in tube furnace at $300{ }^{\circ} \mathrm{C}$ for $1 \mathrm{~h}$, with applied heating rate of $10{ }^{\circ} \mathrm{C} / \mathrm{min}$.

BTF2 was synthesized in the same way as BTF1, the difference was only in changes of weight ratio $\mathrm{BaTiO}_{3}$ to $\mathrm{Fe}\left(\mathrm{NO}_{3}\right)_{3} \cdot 9 \mathrm{H}_{2} \mathrm{O}$. In this sample, $\mathrm{BaTiO}_{3} /$ $\mathrm{Fe}\left(\mathrm{NO}_{3}\right)_{3} \cdot 9 \mathrm{H}_{2} \mathrm{O}$ was set to value 0.8 .

BTF3 was synthesized by co-precipitation method. In aqueous suspension of $\mathrm{BaTiO}_{3}$, warm aqueous solution of $\mathrm{Fe}\left(\mathrm{NO}_{3}\right)_{3} \cdot 9 \mathrm{H}_{2} \mathrm{O}$ (at $\sim 80{ }^{\circ} \mathrm{C}$ ) was added. The solution of $\mathrm{NaOH}(1 \mathrm{~mol} / \mathrm{L})$ was slowly added dropwise into the mixture until reaching $\mathrm{pH}=6$. Obtained mixture was kept on magnetic stirring another $30 \mathrm{~min}$. The yield was washed with distillate water and dried in an oven at $60{ }^{\circ} \mathrm{C}$ over night. Residue was pulverized in a mortar, and subsequently heated in tube furnace at $300{ }^{\circ} \mathrm{C}$ for $1 \mathrm{~h}$, with applied heating rate of $10{ }^{\circ} \mathrm{C} / \mathrm{min}$. Weight ratio $\mathrm{BaTiO}_{3} /$ $\mathrm{Fe}\left(\mathrm{NO}_{3}\right)_{3} \cdot 9 \mathrm{H}_{2} \mathrm{O}$ was 1.2 .

Synthesis method applied for preparation of BTF4 was equivalent as for BTF3, but the weight ratio $\mathrm{BaTiO}_{3} / \mathrm{Fe}\left(\mathrm{NO}_{3}\right)_{3} \cdot 9 \mathrm{H}_{2} \mathrm{O}$ was set to value 0.8 .

BTF5 was prepared as follows. In aqueous suspension of $\mathrm{BaTiO}_{3}$, heat-treated (at $\sim 80{ }^{\circ} \mathrm{C}$ ) aqueous solution of $\mathrm{Fe}\left(\mathrm{NO}_{3}\right)_{3} \cdot 9 \mathrm{H}_{2} \mathrm{O}$ was added. The solution of $\mathrm{NaOH}$ $(1 \mathrm{~mol} / \mathrm{L})$ was slowly added drop by drop into the mixture until the mixture reached $\mathrm{pH}=9$. Obtained mixture was kept on magnetic stirring another $30 \mathrm{~min}$. The yield was washed with distillate water and dried in an oven at $60{ }^{\circ} \mathrm{C}$ over night. Residue was pulverized in a mortar, and heated in furnace at $500{ }^{\circ} \mathrm{C}$ for $1 \mathrm{~h}$, with employed heating rate of $10{ }^{\circ} \mathrm{C} / \mathrm{min}$. Weight ratio
$\mathrm{BaTiO}_{3} / \mathrm{Fe}\left(\mathrm{NO}_{3}\right)_{3} \cdot 9 \mathrm{H}_{2} \mathrm{O}$ was set to 1.2 .

All obtained powders were characterized by XRD using a Philips PW-1050 diffractometer with $\mathrm{Cu} \mathrm{K} \alpha$ radiation and a step/time scan mode of $0.05\left(^{\circ}\right) / \mathrm{s}$.

Raman spectra were collected with a XploRA Raman spectrometer Horiba Jobin Yvon. The system employed a laser at $532 \mathrm{~nm}$, with power of $0.25 \mathrm{MW}$ at the sample. All measurements were performed in the range of $100-1600 \mathrm{~cm}^{-1}$, using the spectrometer equipped with a 2400 lines/mm grating.

Microstructure investigations of the samples were performed using a JEOL JSM-6390 LV scanning electron microscope, coupled with EDS (Oxford Instruments X-MaxN). Powders were covered with gold in order to perform these experimental techniques. As a result, the existence of Au picked in EDS spectra was presented.

TEM measurements were conducted using JEM-1400 $(120 \mathrm{kV})$ equipment. Samples were prepared by sonication of $0.5 \mathrm{mg}$ dry powder in $1 \mathrm{~mL}$ of ethanol for $2 \mathrm{~h}$. Suspensions were deposited onto carbons meshes.

Magnetization measurements were performed using a modified Maxwell method, based on the actions of a magnetic field $55 \mathrm{kA} / \mathrm{m}$ on the samples. Thermomagnetic measurements were done with continuous heating from room temperature up to $200{ }^{\circ} \mathrm{C}$ with the rate $10{ }^{\circ} \mathrm{C} / \mathrm{min}$.

Electrical measurements were performed on compacted ceramic material. Samples were pressed in the same diameter press tool and with same thickness. Monitoring was performed in air atmosphere using HIOKI 3532-50 LCR HiTESTER instrument. The applied frequency range was $50 \mathrm{~Hz}-5 \mathrm{MHz}$, and the temperature varied from 20 to $200{ }^{\circ} \mathrm{C}$.

\section{Results and discussion}

The room temperature XRD patterns of all prepared samples (BTF1-BTF5) are presented in Fig. 1.

The all observed reflections are identified using JCPDS cards (075-2120 for $\mathrm{BaTiO}_{3}, 071-0729$ for $\mathrm{FeO}(\mathrm{OH}), 071-0729$ for $\mathrm{NaNO}_{2}, 065-0390$ for $\gamma-\mathrm{Fe}_{2} \mathrm{O}_{3}$, 084-0309 for $\alpha-\mathrm{Fe}_{2} \mathrm{O}_{3}, 076-1821$ for $\beta-\mathrm{Fe}_{2} \mathrm{O}_{3}$, and 088-0315 for $\mathrm{Fe}_{3} \mathrm{O}_{4}$ ). Samples synthesized at $\mathrm{pH}=12$ (BTF1 and BTF2) show the presence of a few different phases of iron oxide, along with $\mathrm{FeO}(\mathrm{OH})$ and $\mathrm{NaNO}_{2}$ phases, besides the $\mathrm{BaTiO}_{3}$. All reflections of $\mathrm{BaTiO}_{3}$ phase are sharp and intensive, indicating the tetragonal 

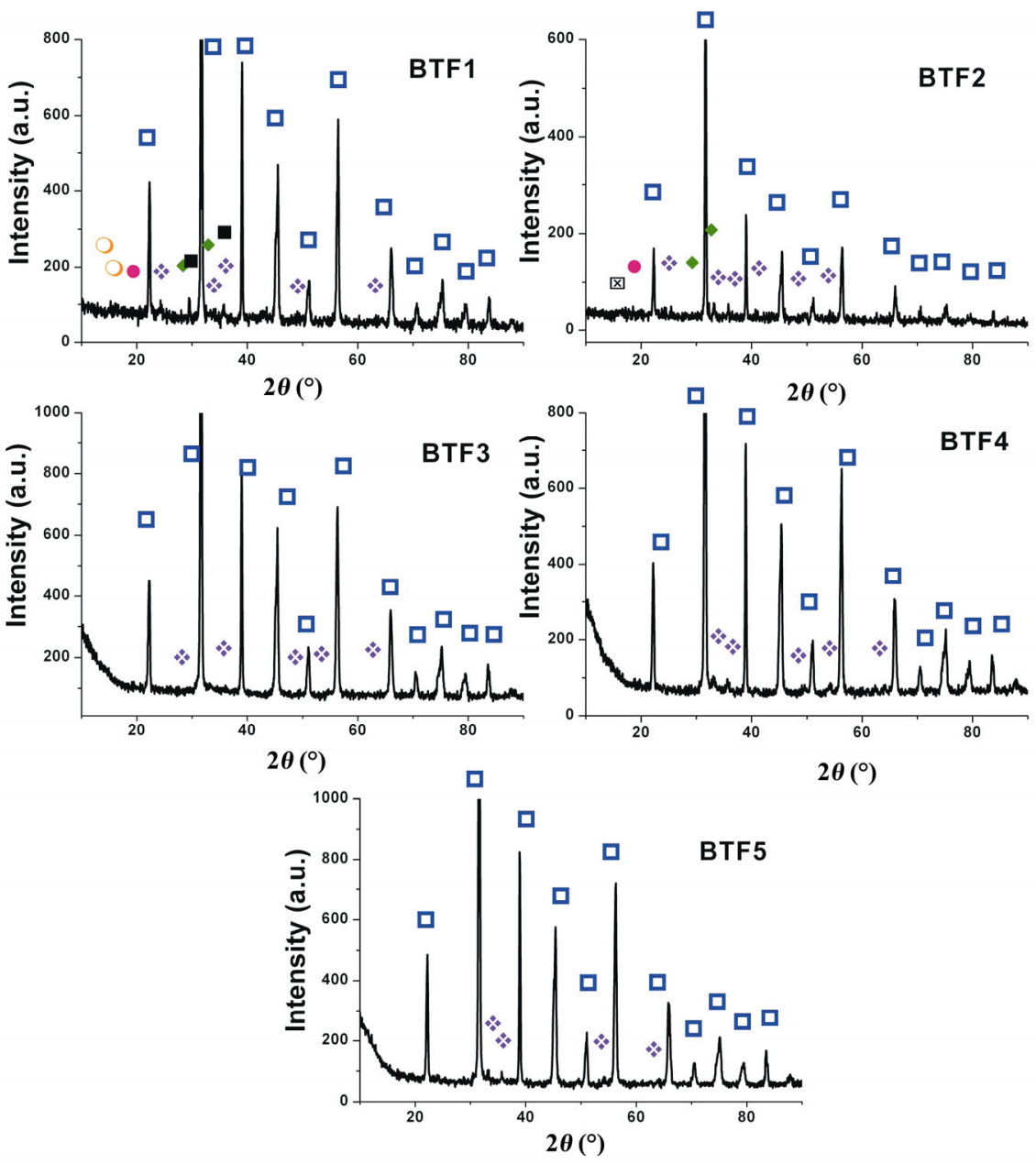

$$
\begin{aligned}
& \mathrm{D-BaTiO}_{3} \bullet-\mathrm{NaNO}_{2}, \bullet-\mathrm{FeO}(\mathrm{OH}), \bigcirc-\gamma-\mathrm{Fe}_{2} \mathrm{O}_{3} \text {, } \\
& -\alpha-\mathrm{Fe}_{2} \mathrm{O}_{3}, \square-\mathrm{Fe}_{3} \mathrm{O}_{4}, \quad-\beta-\mathrm{Fe}_{2} \mathrm{O}_{3}
\end{aligned}
$$

Fig. 1 XRD patterns of the samples BTF1-BTF5 measured at room temperature.

crystal structure (Fig. 1). Presence of $\mathrm{NaNO}_{2}$ indicates that washing with distillate water wasn't sufficient for total removing of the nitrates. Among the iron oxides, the $\alpha-\mathrm{Fe}_{2} \mathrm{O}_{3}, \beta-\mathrm{Fe}_{2} \mathrm{O}_{3}$, and $\gamma-\mathrm{Fe}_{2} \mathrm{O}_{3}$ modifications of $\mathrm{Fe}_{2} \mathrm{O}_{3}$ phase, $\mathrm{Fe}_{3} \mathrm{O}_{4}$ were detected as well in the BTF1 and BTF2 samples. It is well known that the $\gamma-\mathrm{Fe}_{2} \mathrm{O}_{3}$ (maghemite) and the $\mathrm{Fe}_{3} \mathrm{O}_{4}$ (magnetite) are usually reported as spinel crystal structures at room temperature, with ferrimagnetic properties, but the latter contains both $\mathrm{Fe}^{2+}$ and $\mathrm{Fe}^{3+}$ ions, while in the former, all the iron ions are present in trivalent state and the charge neutrality of the unit cell sustains via partial $\mathrm{Fe}$ vacancy disorder. Actually, maghemite can be considered as an iron-deficient form of magnetite [29]. Hematite $\left(\alpha-\mathrm{Fe}_{2} \mathrm{O}_{3}\right)$ belongs to the space group $R \overline{3} c$ and it is reported as canted antiferromagnetic (weak ferromagnetic) in the temperature range between its Morin and Néel temperatures. The maghemite is metastable compared with hematite, and phase transformation $\gamma-\mathrm{Fe}_{2} \mathrm{O}_{3} \rightarrow$ $\alpha-\mathrm{Fe}_{2} \mathrm{O}_{3}$ occurs approximately at $400{ }^{\circ} \mathrm{C}$ [30]. $\beta-\mathrm{Fe}_{2} \mathrm{O}_{3}$ has body-centered and cubic crystal structure, which belongs to the space group $I a \overline{3}$. Its stabile form occurs only in nanosized dimensions of materials and it exhibits the phase transition into $\alpha-\mathrm{Fe}_{2} \mathrm{O}_{3}$ during heating. $\beta-\mathrm{Fe}_{2} \mathrm{O}_{3}$ is the only phase of iron oxides that behaves paramagnetically at room temperature [31]. According to our XRD analyses of the BTF1 and BTF2 samples, significantly higher intensities of the barium titanate reflections comparing to the reflections of iron oxides are observed, and they are the consequence of the weight ratio of starting components that were used. The mass percentages of detected phases for all samples are given in Table 1.

As it can be seen, with a decrease of $\mathrm{pH}$ value during 
Table 1 Mass percent of all detected phases in the samples BTF1-BTF5

\begin{tabular}{cccccccc}
\hline & $\mathrm{BaTiO}_{3}$ & $\alpha-\mathrm{Fe}_{2} \mathrm{O}_{3}$ & $\beta-\mathrm{Fe}_{2} \mathrm{O}_{3}$ & $\gamma-\mathrm{Fe}_{2} \mathrm{O}_{3}$ & $\mathrm{Fe}_{3} \mathrm{O}_{4}$ & $\mathrm{FeO}(\mathrm{OH})$ & $\mathrm{NaNO}_{2}$ \\
\hline BTF1 & 50.4 & 12.5 & - & 16.5 & 3.9 & 3.7 & 13.1 \\
$\mathrm{BTF} 2$ & 62.7 & 10.8 & 10.4 & - & 2.2 & 6.6 & 7.2 \\
$\mathrm{BTF} 3$ & 90.6 & 9.4 & - & - & - & - & - \\
$\mathrm{BTF} 4$ & 94.9 & 5.1 & - & - & - & - & - \\
BTF5 & 90.4 & 9.6 & - & - & - & - & - \\
\hline
\end{tabular}

the synthesis, a significantly lower amount of iron compounds was formed. So, in the samples BTF3-BTF5, only the hematite and $\mathrm{BaTiO}_{3}$ phases were present, although samples synthesized at lower $\mathrm{pH}$ purer phase composition was obtained. Furthermore, an interesting phenomenon was noticed during observation of amount of formed iron-based oxides. It was detected that in the samples prepared at the same $\mathrm{pH}$ value and same procedure, but with higher weight ratio of $\mathrm{BaTiO}_{3}$ to $\mathrm{Fe}\left(\mathrm{NO}_{3}\right)_{3}$ (sample BTF1 with respect to BTF2, as well as the sample BTF3 with respect to BTF4), the higher mass percentage of the formed iron-oxide phases in the final obtained samples occurred. It should be noticed that the coating, not only changes the interactions of the particles with the surrounding environment but also allows modification of the particle properties. Therefore, new functionalities can be imparted to the cores depending on the properties of the shell. Although, in some multiferroic $\mathrm{BaTiO}_{3}$ based core/shell structures such as $\mathrm{CoFe}_{2} \mathrm{O}_{4} / \mathrm{BaTiO}_{3}, \mathrm{BaTiO}_{3}$ can act as a shell, it has been found that in some other core/shell composites, $\mathrm{BaTiO}_{3}$ may act as a nucleous for the shell formation as well $[32,33]$. In the case of the BTF1 sample, the last conclusion could be also made even just for the ferrimagnetic phases and therefore it could be assumed that the particles of $\mathrm{BaTiO}_{3}$ act as nucleus centers for synthesis of ferrimagnetic phases and promote their formation.

The Raman spectra (Fig. 2) of the investigated samples showed peaks of barium titanate, two iron oxides (hematite: $\alpha-\mathrm{Fe}_{2} \mathrm{O}_{3}$ and magnetite: $\mathrm{Fe}_{3} \mathrm{O}_{4}$ ) and one oxyhydroxide (lepidocrocite: $\gamma-\mathrm{FeOOH}$ ). The presence of $\mathrm{BaCO}_{3}$ was observed only in $\mathrm{BTF} 1$ sample, while the occurrence of the strongest line of $\gamma-\mathrm{Fe}_{2} \mathrm{O}_{3}$ (maghemite) could only be indirectly perceived $[29,34,35]$. The $\mathrm{NaNO}_{2}$ modes [36] weren't detected, although the presence of $\mathrm{NaNO}_{2}$ was ascertained by X-ray diffractometry. This is probably caused by the fact that $\mathrm{X}$-ray method shows the averaged results of a given volume, while Raman provides more local images

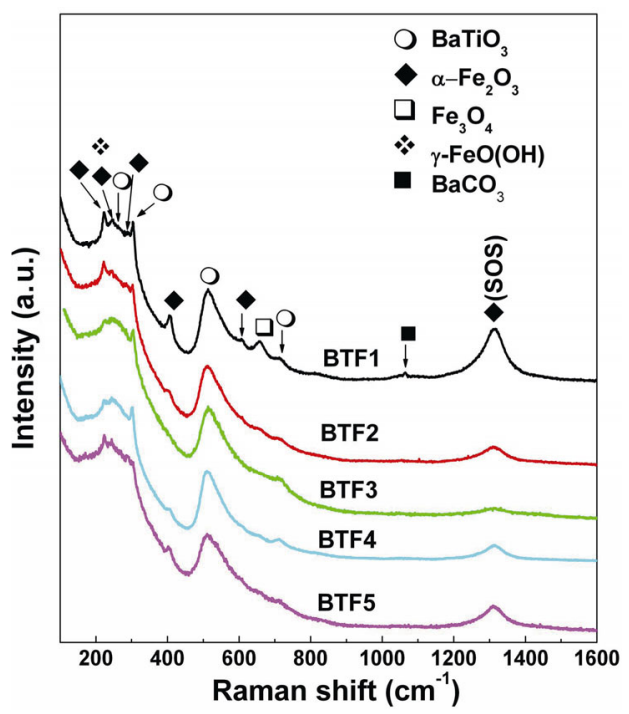

Fig. 2 Raman spectra of the BTF1-BTF5 samples.

corresponding to the thin surface layer of the sample. Namely, $\mathrm{NaNO}_{2}$, which was detected by X-ray diffractometry, is probably related to the residual $\mathrm{NaNO}_{2}$ within the agglomerates, and hence it is not removed by washing with distilled water. It seemed that the residual $\mathrm{NaNO}_{2}$ wasn't sufficiently near to the surface of these agglomerates in order to be detected by Raman measurement. The appearance of peak at $\sim 303 \mathrm{~cm}^{-1}$, in all samples, confirmed the existence of $\mathrm{BaTiO}_{3}$ tetragonal modification [37-39].

Detected modes of hematite in BTF1 powder include not only the $A_{1 \mathrm{~g}}$ mode at $223 \mathrm{~cm}^{-1}, E_{\mathrm{g}}$ mode at $406 \mathrm{~cm}^{-1}$, and $\mathrm{E}_{\mathrm{g}}$ at $609 \mathrm{~cm}^{-1}$, but also the $2 \mathrm{E}$ mode at $\sim 1315 \mathrm{~cm}^{-1}$, where the last one presents overtone originated from the $2^{\text {nd }}$ order scattering (marked as SOS in Fig. 2) [34].

However, the strongest mode of $\gamma-\mathrm{Fe}_{2} \mathrm{O}_{3}$ phase, which usually occurs as a very broad peak at $\sim 1360 \mathrm{~cm}^{-1}$, may give a certain contribution to the peak at $\sim 1315 \mathrm{~cm}^{-1}$ as well. The $\mathrm{E}_{\mathrm{g}}$ mode of hematite at $\sim 288 \mathrm{~cm}^{-1}$ is poorly noticeable, because of its overlapping with the broad mode of barium titanate which occurs at $255-260 \mathrm{~cm}^{-1}$. It can be assumed that the peak at $245 \mathrm{~cm}^{-1}$ mostly originates from vibrations in $\gamma$-FeOOH phase, because the strongest line of $\gamma-\mathrm{FeOOH}$ appears at that position, but one of the weaker hematite lines may additionally contribute to the mentioned peak. Raman line of the magnetite at $658 \mathrm{~cm}^{-1}$, which is the strongest line in the pure magnetite spectrum, was also observed in the BTF1 powder $[29,34,35]$. Among the barium titanate modes in the BTF1 powder, several peaks were noticed. Peaks at 303 and $514 \mathrm{~cm}^{-1}$ are clearly visible, where 
the former is characteristic of the tetragonal phase of $\mathrm{BaTiO}_{3}$ and corresponds to the set of modes: $\mathrm{B}_{1}+\mathrm{E}$ (2LO) + E (3TO), while the latter can be attributed to $\mathrm{E}$ (4TO) $+\mathrm{A}_{1}(3 \mathrm{TO})$ modes. The weak and broad peak at $715 \mathrm{~cm}^{-1}$ corresponds to $\mathrm{A}_{1}(3 \mathrm{LO})+\mathrm{E}(4 \mathrm{LO})$ modes [37-39] of $\mathrm{BaTiO}_{3}$, while the peak at $255-260 \mathrm{~cm}^{-1}$ originates from $\mathrm{A}_{1}(2 \mathrm{TO})$ mode. In addition, very weak feature of the $\mathrm{BaCO}_{3}$ strongest mode [35] situated at $1064 \mathrm{~cm}^{-1}$ was also observed in the considered spectra. It probably comes from the carbonate formed on the surface, which is common in the preparation of barium titanate and other systems based on $\mathrm{BaTiO}_{3}$. Due to its low concentrations, $\mathrm{BaCO}_{3}$ was not detected by $\mathrm{X}$-ray diffractometry.

In the BTF2 sample, hematite $\mathrm{E}_{\mathrm{g}}$ modes and 2E mode are less pronounced with respect to the barium titanate modes, indicating the lower amount of $\alpha-\mathrm{Fe}_{2} \mathrm{O}_{3}$, which is in good agreement with results obtained by X-ray analyses presented in Table 1. Contribution of maghemite phase doesn't exist, or is present in a negligible amount. The Raman peak of magnetite is also very weakly manifested. All these observations are consistent with the results of X-ray diffraction. It should be noticed that the mode at $303 \mathrm{~cm}^{-1}$, characteristical for $\mathrm{BaTiO}_{3}$ tetragonal modification, decreases in intensity, indicating the loose of vibration energy with an increase of the stress due to core/shell coupling [39-41]. Since, this mode disappears with the phase transition of tetragonal barium titanate crystal structure into the cubic one, it could be concluded that its decrease for the BTF2-BTF5 samples will result in the change of the tetragonality within $\mathrm{BaTiO}_{3}$ lattice.

In the powders BTF3 and BTF4, Raman lines of iron oxides are the least detectable. It is in accordance with X-ray analysis which shows the highest percentage of $\mathrm{BaTiO}_{3}$ for these powders. Actually, among the lines of iron oxides only a few modes of hematite are observed in the form of the weak features, with a barely noticeable trace of the strongest magnetite and lepidocrocite lines. The amounts of the last two mentioned phases were below the limit of detection by X-ray diffractometry, as it can be seen from Table 1.

Raman spectrum of the BTF5 sample confirmed the change in $\mathrm{BaTiO}_{3} / \alpha-\mathrm{Fe}_{2} \mathrm{O}_{3}$ ratio with respect to the BTF4 powder, in terms of the re-increase of hematite share.

Microstructure of the starting $\mathrm{BaTiO}_{3}$ powder (Fig. 3 ) shows that smaller particles, with average diameter of 200-300 nm, dominate. Further, the presence of soft

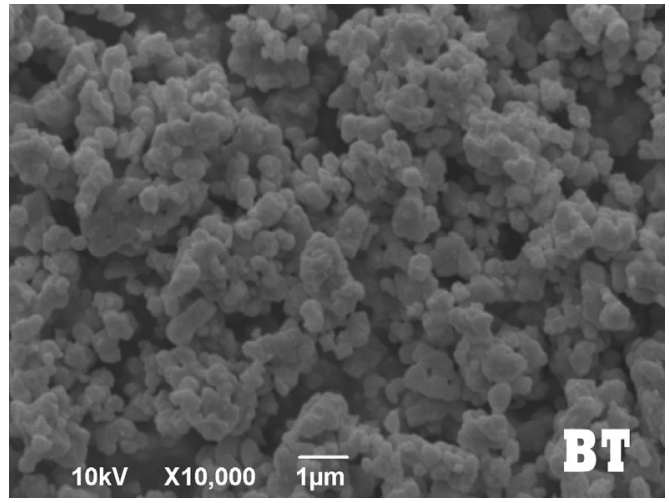

Fig. 3 SEM image of pure $\mathrm{BaTiO}_{3}$.

agglomerates is evident, and their sizes are 1-1.2 $\mu \mathrm{m}$.

SEM, EDS, along with mapping of elements and TEM images, for the BTF1 sample, are presented in Fig. 4. According to TEM analysis, the presence of needle shaped shell around core particles was observed (Fig. 4(d)). The existence of different iron oxides was confirmed by XRD analyses (Fig. 1). Furthermore, according to SEM analysis, the existence of agglomerates has been noticed as well. The remained $\mathrm{NaNO}_{2}$ was proven by EDS and showed in Figs. 4(b) and 4(c). Mapping of the elements indicate the formation of the almost uniform coating of $\mathrm{BaTiO}_{3}$ powder with synthesized oxides.

SEM and TEM images of the BTF2 sample (Fig. 5(a)) indicate more uniform distribution of smaller (Fe-oxides) particles around $\mathrm{BaTiO}_{3}$ core. The remains of $\mathrm{NaNO}_{2}$ weren't detected in EDS of this sample, probably due to the selection of the shooting spot and smaller amounts of residual sodium nitrate. Also, it is noticeable that shell particles haven't dominantly needle shaped. Having in mind that for the samples BTF1 and BTF2 all other synthesis parameters are identical, we concluded that the amount of added ferric nitrate determinates shape of the shell particles. TEM image has confirmed almost uniform coating of core with shell. The average size of the well separated core particles is $\sim 100 \mathrm{~nm}$, and shell thickness is approximately $20 \mathrm{~nm}$. Better coupling between interior core and exterior shell (without dominantly needle-shape) parts can be also observed.

SEM image of the sample BTF3 (Fig. 6(a)) shows significantly smaller amount of formed $\mathrm{Fe}_{2} \mathrm{O}_{3}$ and considerably more particles $\mathrm{BaTiO}_{3}$ without shell. This is probably due to lower $\mathrm{pH}$ of synthesis and the absence of additional ultrasound treatment. The chemical reaction between the $\mathrm{Fe}\left(\mathrm{NO}_{3}\right)_{3} \cdot 9 \mathrm{H}_{2} \mathrm{O}$ and added $\mathrm{NaOH}$ within this preparation conditions hasn't 
completed. EDS (Fig. 6(b)) confirms presence of all introduced elements ( $\mathrm{Ba}, \mathrm{Ti}, \mathrm{O}$, and $\mathrm{Fe}$ ). According to the mapping of the elements, and the formed $\mathrm{Fe}_{2} \mathrm{O}_{3}$ is not evenly dispersed over the $\mathrm{BaTiO}_{3}$. TEM image of the BTF3 (Fig. 6(d)) shows non-uniform distribution of shell around core (dark part of the image). The existence of agglomerates is clearly visible, along with areas without shell.

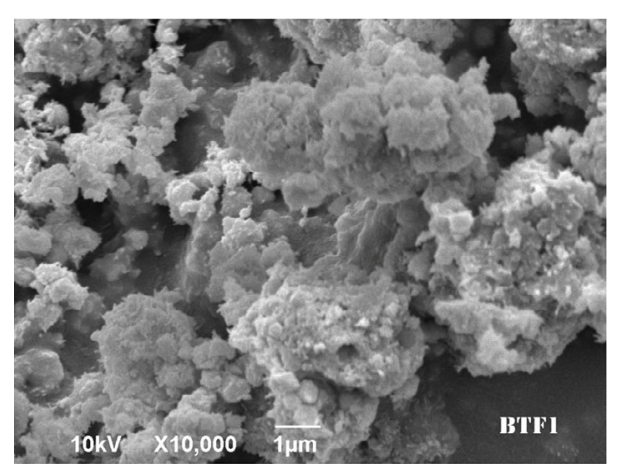

(a)
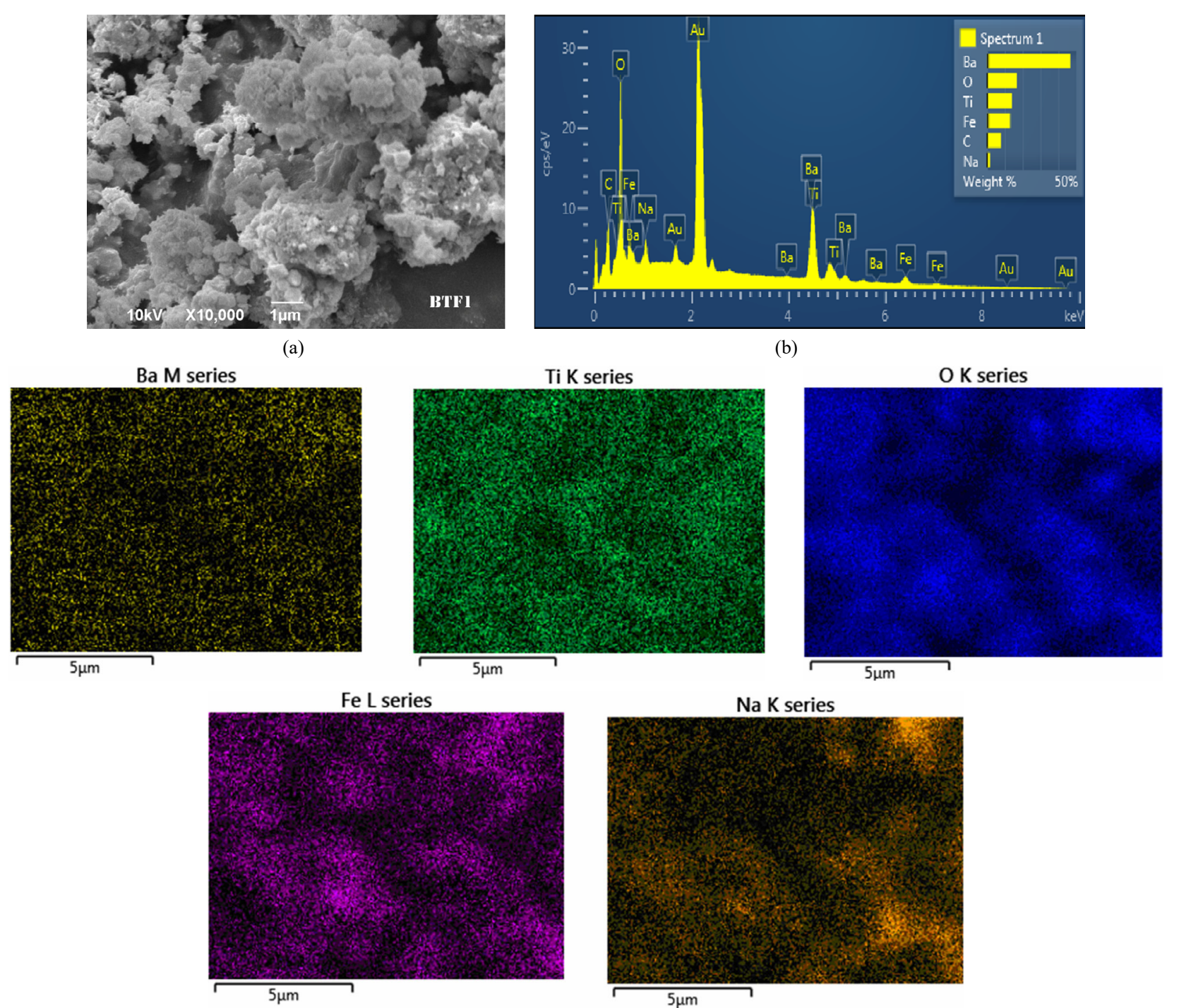

(b)

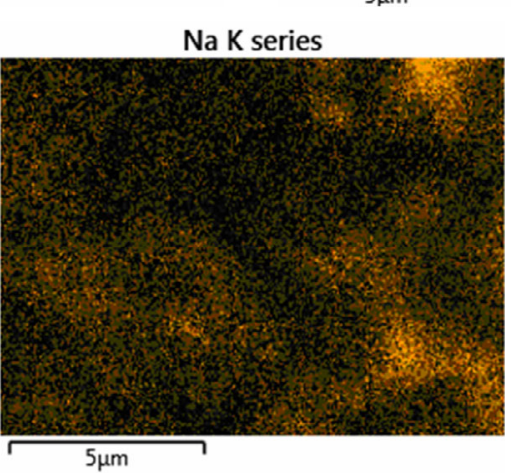

(c)

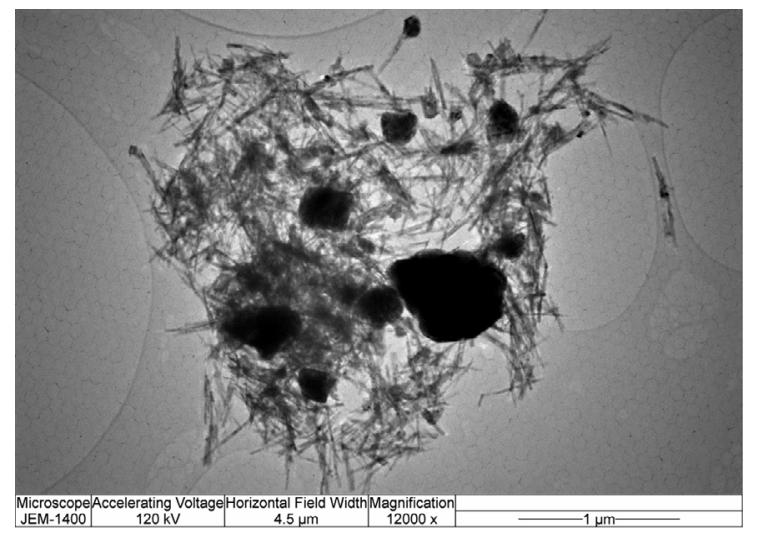

(d)

Fig. 4 (a) SEM; (b) EDS; (c) mapping of elements; (d) TEM for the sample BTF1. 


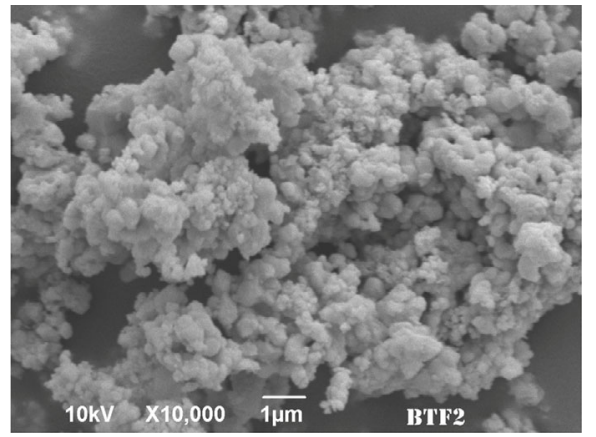

(a)

Ba $L \alpha 1$

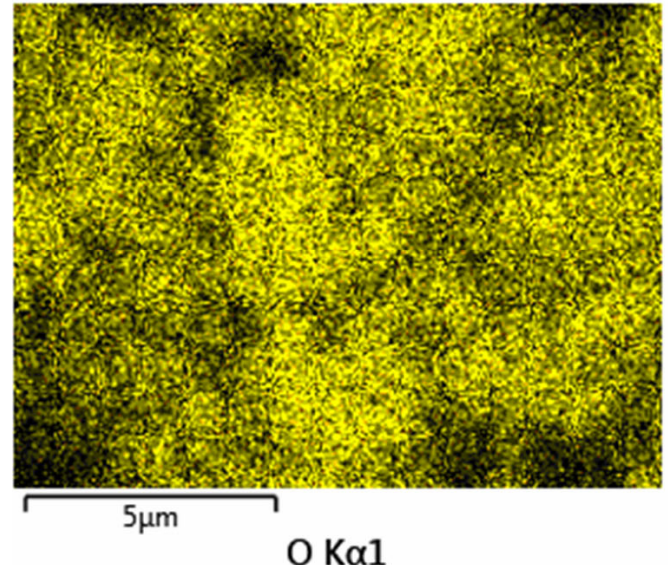

$\mathrm{O} K \alpha 1$

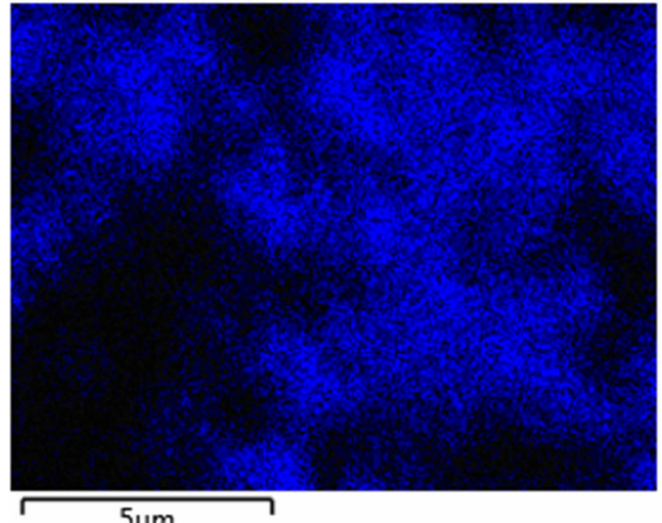

$5 \mu \mathrm{m}$

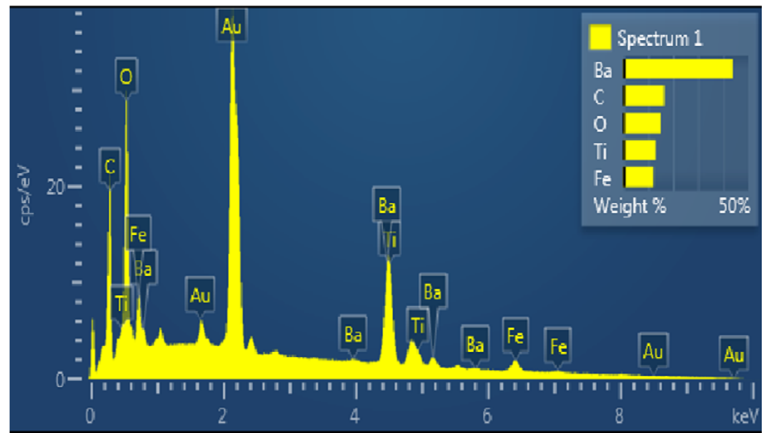

(b)

Ti $K \alpha 1$

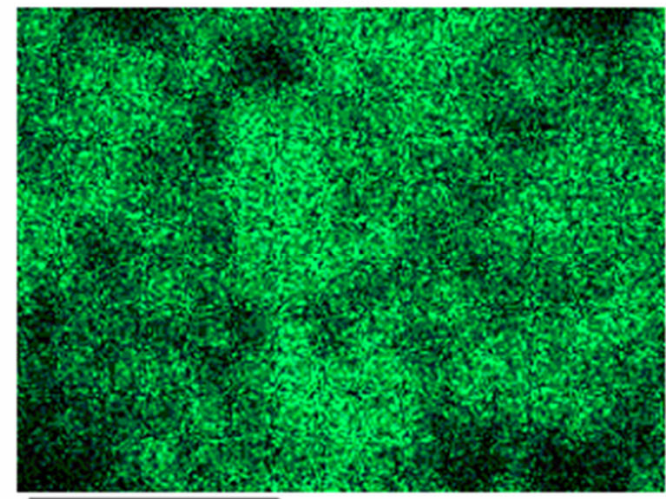

$5 \mu \mathrm{m}$

Fe $L \alpha 12$

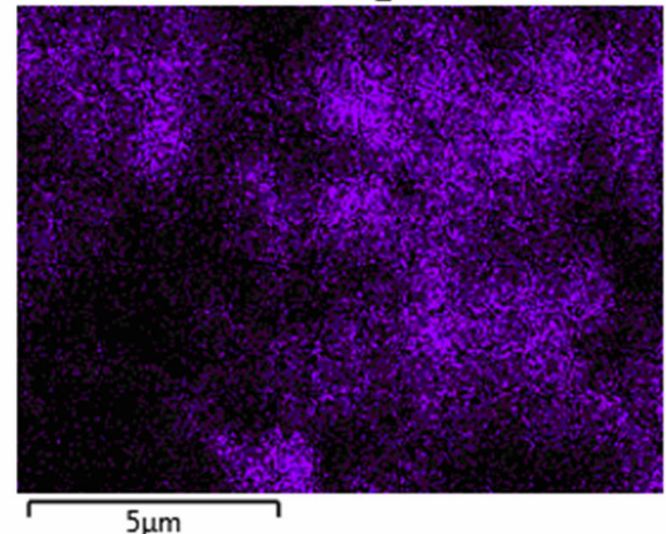

(c)

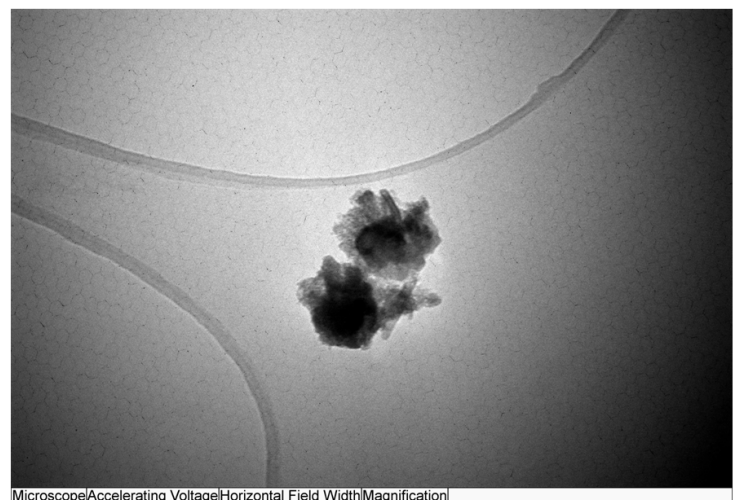

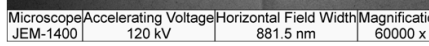

(d)

Fig. 5 (a) SEM; (b) EDS; (c) mapping of elements; (d) TEM for the sample BTF2. 


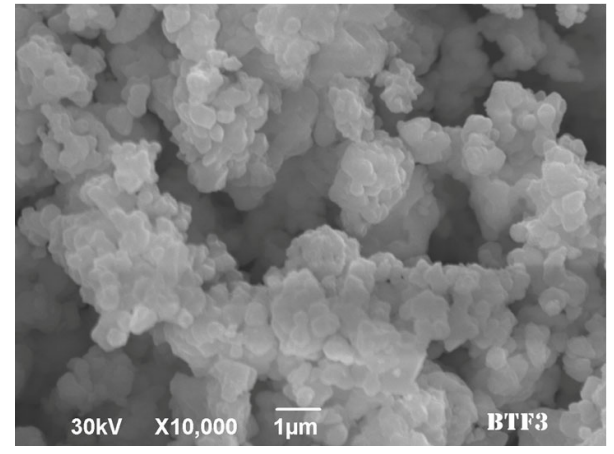

(a)

$\mathrm{Ba} L \alpha 1$

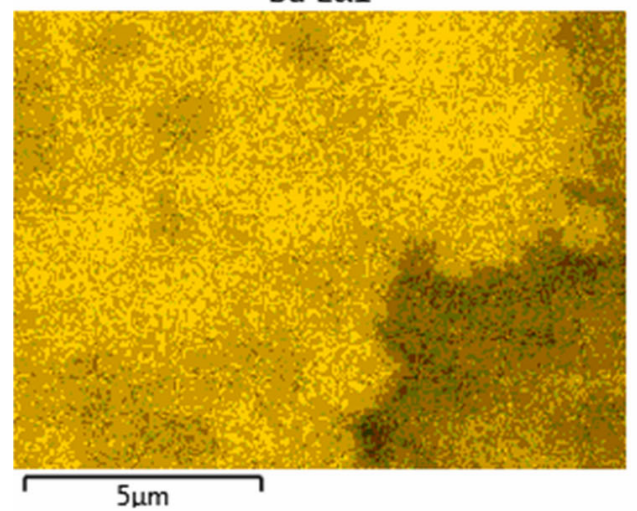

$\mathrm{O} \mathrm{K} \alpha 1$

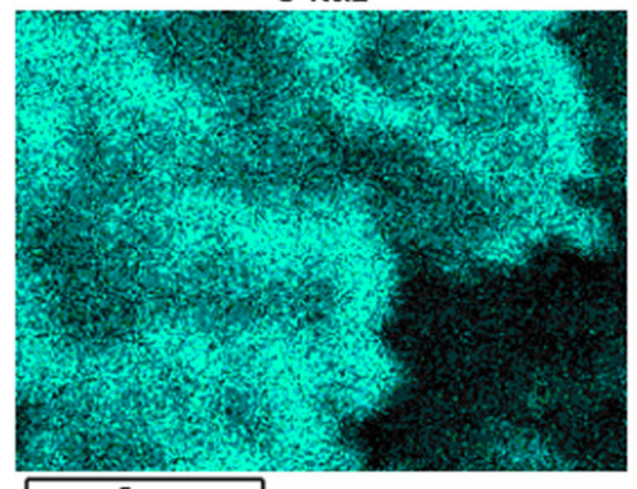

$5 \mu \mathrm{m}$

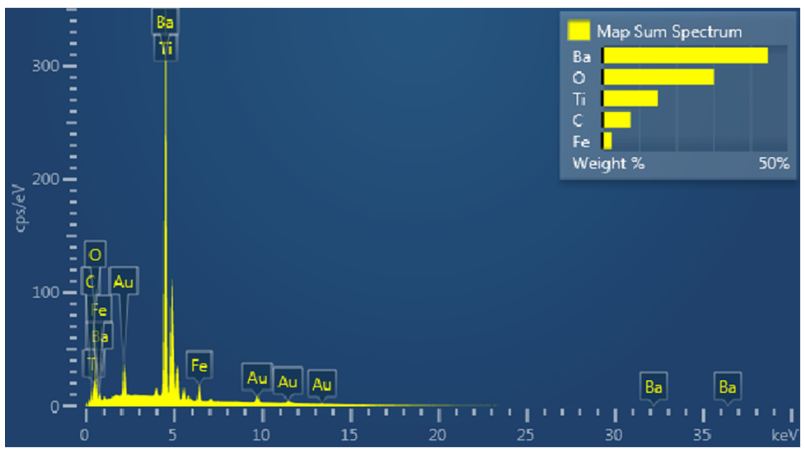

(b)

Ti K $\alpha 1$

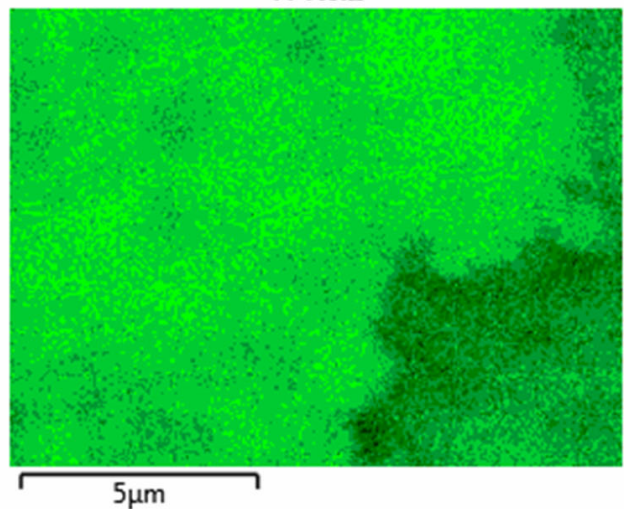

Fe $K \alpha 1$

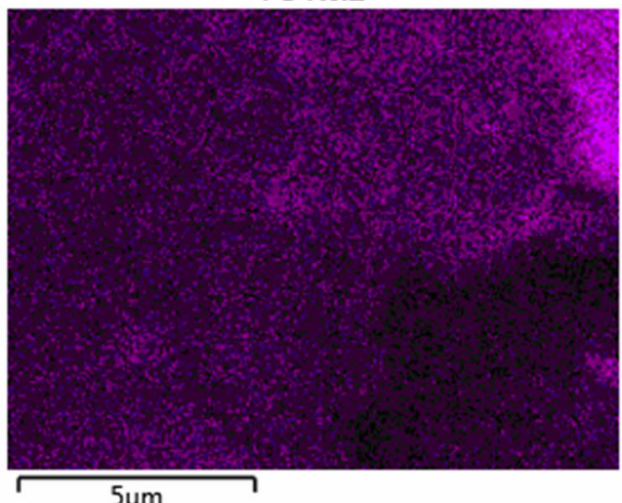

(c)

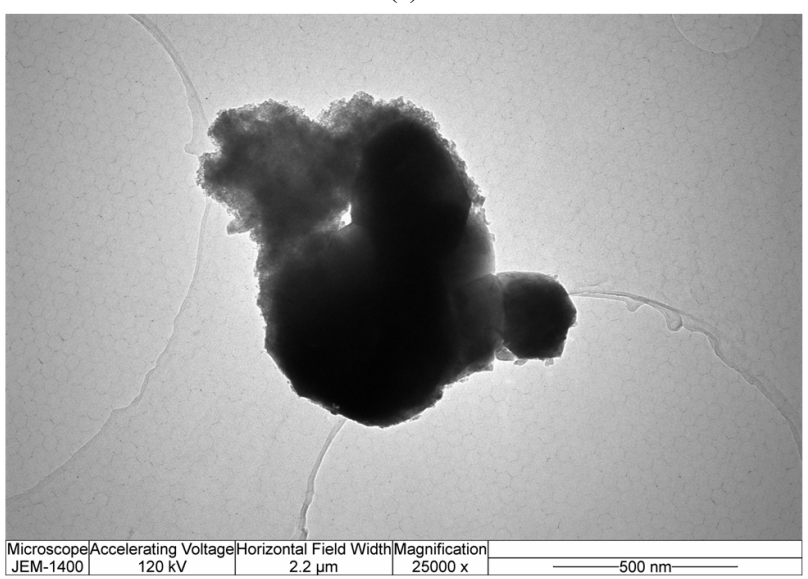

(d)

Fig. 6 (a) SEM; (b) EDS; (c) mapping of elements; (d) TEM for the sample BTF3. 
The main characteristic of the microstructure for the BTF4 (Fig. 7(a)) is an obviously smaller number of particles which are covered by shell particles. It is in a good correlation with XRD and Raman measurements data (Fig. 1, Fig. 2, and Table 1), where it is shown that the smaller amount of iron-oxide phase was formed. Mapping (Fig. 7(c)) confirmed that $\mathrm{Fe}$ wasn't uniformly arranged on the surface of $\mathrm{BaTiO}_{3}$. TEM image (Fig. 7(d)) verifies the existence undeveloped core/shell structures which is in a good agreement with SEM and EDS analyses, as well as with the data obtained by XRD and Raman.

Morphology of the BTF5 sample, showed in Fig. $8(\mathrm{a})$, is very similar with microstructure of BTF3 (Fig. $6(\mathrm{a}))$. The presence of formed core/shell structure is observed, along with pure $\mathrm{BaTiO}_{3}$ particles and agglomerates. Mapping of detected elements indicates areas where $\mathrm{Fe}_{2} \mathrm{O}_{3}$ is localized. Figure 8(d) presents TEM micrograph of the BTF5 sample. It is noticeable that spherically shaped shell particles are strongly bonded to core, thus indicating strain effects noticed within Raman spectra. Non-uniform distribution, around cores, is clearly detected.

The dependence of magnetization versus temperature for all five samples is shown in Fig. 9. $M-T$ curves show that the value of ferroelectric transition temperature $\left(T_{\mathrm{FE}}\right)$ is in the range $100-120{ }^{\circ} \mathrm{C}$, as a result of the coupling between the ferromagnetic and ferroelectric order parameters $[1,5,6]$. The most pronounced transition was observed within BTF2 and BTF3 samples.

It has been noticed that the highest $T_{\mathrm{FE}}$ has been detected for BTF1 sample. This indicates that for this sample, bonds between core and shell are not strong enough and the strain isn't pronounced so much. The shifting of $T_{\mathrm{FE}}$ toward lower values (for BTF2-BTF5) indicates stronger coupling between the magnetism and ferroelectricity in these samples [6,42]. Similar behavior, that strain originated from $\mathrm{BaTiO}_{3}$ core strongly affects the electrical properties of $\mathrm{Fe}_{3} \mathrm{O}_{4}$ shell, and vice versa, was noticed by Koo et al. [14] and Curecheriu et al. [43]. Coupling between magnetic and ferroelectric phases is reflected mostly in values of $\mathrm{ME}$ coupling coefficient. Mahajan et al. [44] found maximum value of $(\mathrm{d} E / \mathrm{d} H)$ of $140 \mu \mathrm{V} /(\mathrm{cm} \cdot \mathrm{Oe})$ at about 1500 Oe for cobalt ferrite-barium titanate composites. $\alpha-\mathrm{Fe}_{2} \mathrm{O}_{3}$ and $\mathrm{BaTiO}_{3}$ composite materials obtained by solid state reaction show maximum value of $0.05 \%$ for magnetocapacitance at $4000 \mathrm{Oe}$. It can be concluded that low value of magnetocapacitance can originate from the presence of large number of interfaces, poor connectivity between $\mathrm{BaTiO}_{3}$ grains and magnetic phases [45].

The second transition near $200{ }^{\circ} \mathrm{C}$ was noticed, and is attributed to ferromagnetic transition which is very close to the value obtained by Deka et al. [42]. Furthermore, the highest values of magnetization were observed for BTF2 and BTF3 samples.

The variation of the capacitance of the samples BTF2 and BTF3 as a function of frequencies is shown in Fig. 10. At high frequencies, the capacitance is of order of magnitude $10^{-11}-10^{-10} \mathrm{~F}$, but it increases significantly at lower frequencies, reaching the value of $10^{-8}$ and $10^{-6} \mathrm{~F}$ at $10^{2} \mathrm{~Hz}$, for the BTF3 and BTF2 respectively. Observed trend of capacitance enhancement and the dispersion observed at lower frequencies are common features of the $\mathrm{BaTiO}_{3}-$ magnetic composites and it indicates that extrinsic phenomena, such as Maxwell-Wagner interfacial polarization and conductivity in the magnetic phases contribute to the capacitance value. Contributions are dominantly appearing at low frequencies, similar as it was shown in literature $[43,45]$. The apparent capacitance of composites increases rapidly with decreasing frequency, because of conductivity effects. Taking into account that samples were prepared in the same way (same die tool, same applied pressure, and same weight, etc.), the higher capacitance of BTF2 sample was expected because of significant differences in iron oxides amount within samples BTF2 and BTF3, as shown in Table 1 .

At higher frequencies, where the charge defects aren't active any more, capacitance gravitates toward its intrinsic value. Partially minor values of capacitance of comparison to pure $\mathrm{BaTiO}_{3}$, is expected due to the large number of the non-ferroelectric grain boundaries as well as reduction of tetragonality [43], and detected by Raman measurements.

Effect of changes in $Q$ factor with increase in heating temperature for BTF2 and BTF3 samples is presented in Fig. 11. The broad peak obtained for the sample BTF2 between $110-120{ }^{\circ} \mathrm{C}$ is characteristic of ferroelectric transition of $\mathrm{BaTiO}_{3}$. For the BTF3 sample, this peak was shifted to the lower temperatures, indicating some coupling between the magnetism and ferroelectricity within the sample, which was confirmed by magnetization measurement. Further, it was found that partially $\mathrm{Fe}$ substitution in $\mathrm{BaTiO}_{3}$ ceramics, the 


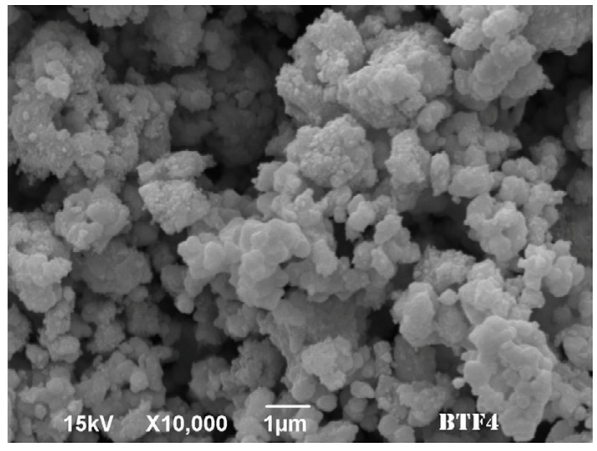

(a)
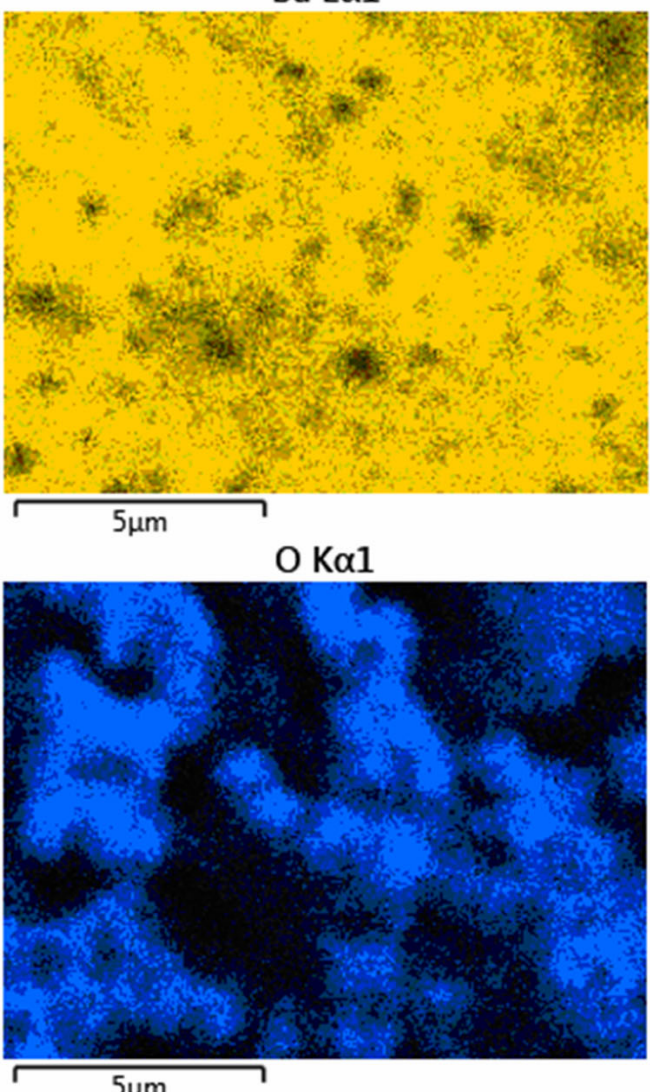

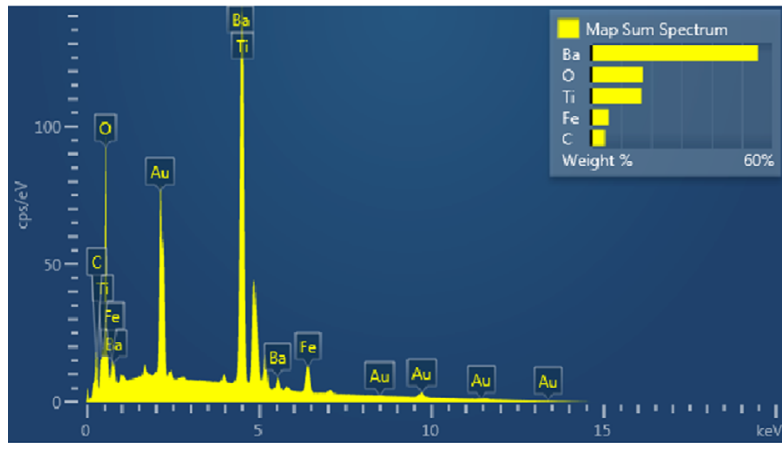

(b)

Ti K $\alpha 1$

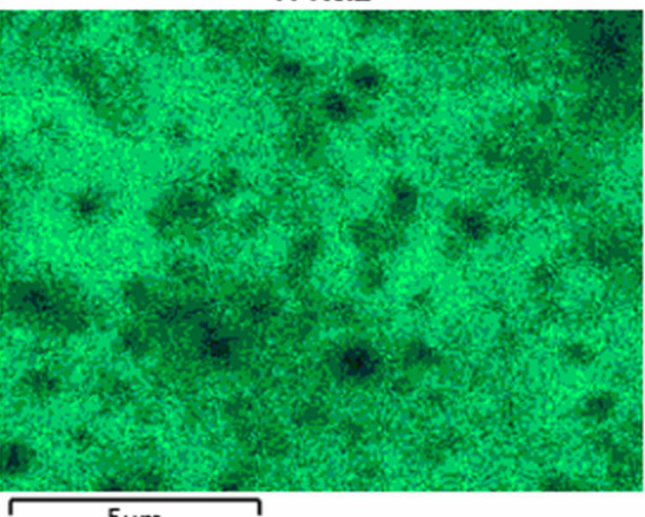

$\mathrm{Fe} K \alpha 1$

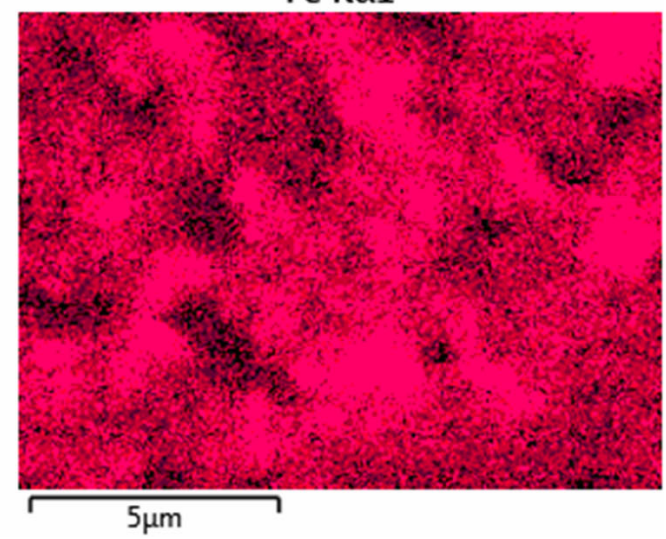

(c)

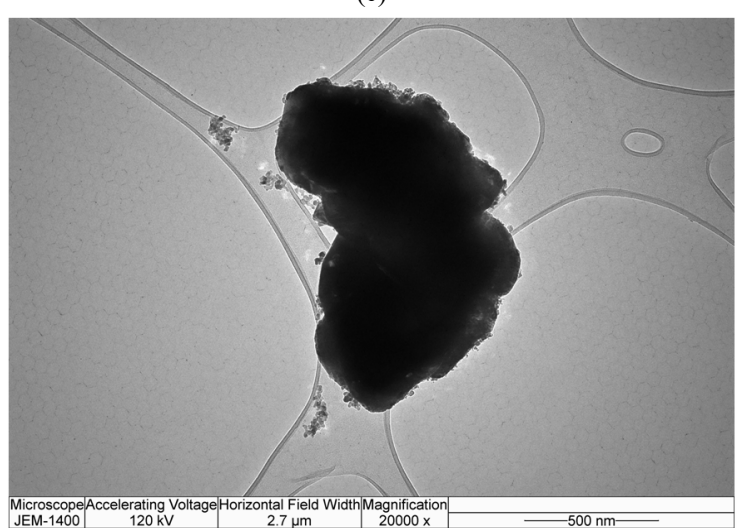

(d)

Fig. 7 (a) SEM; (b) EDS; (c) mapping of elements; (d) TEM for the sample BTF4. 


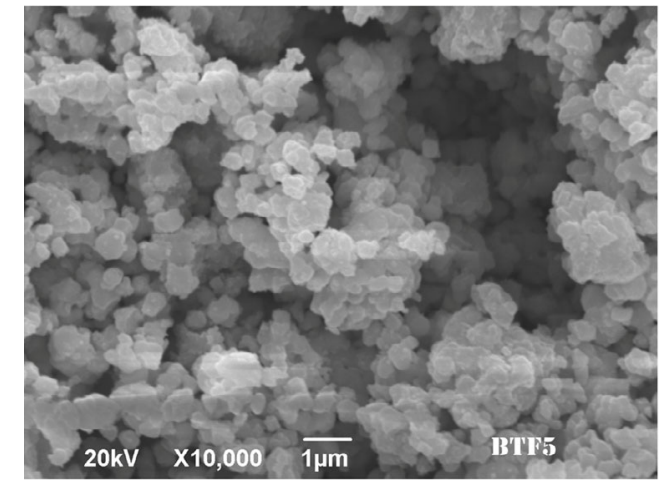

(a)

Ba $L \alpha 1$

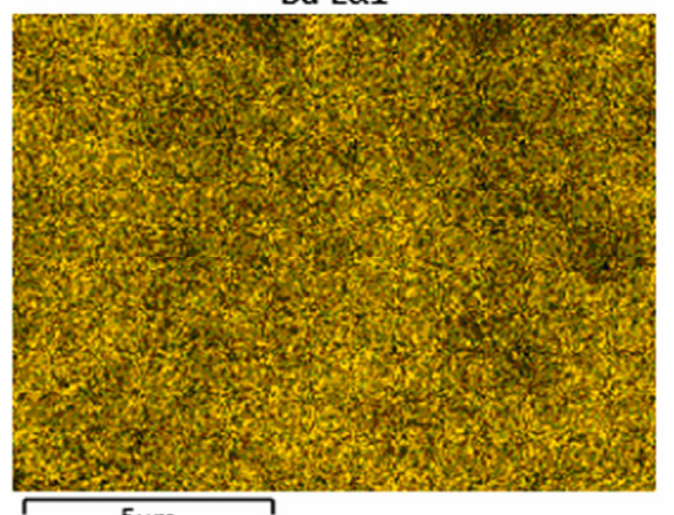

$\mathrm{O} K \alpha 1$

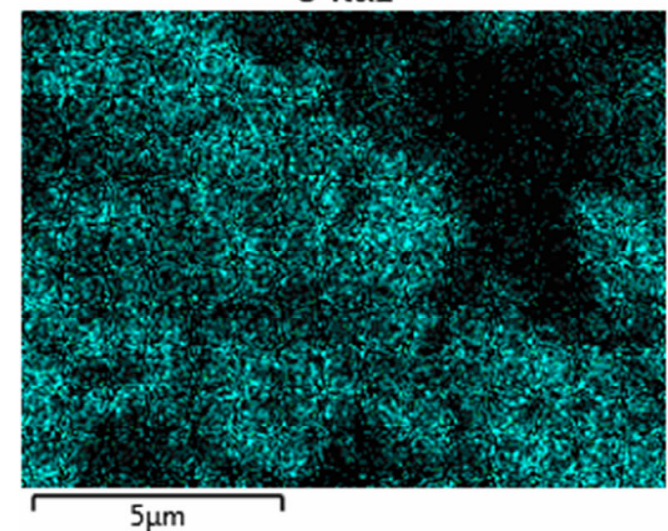

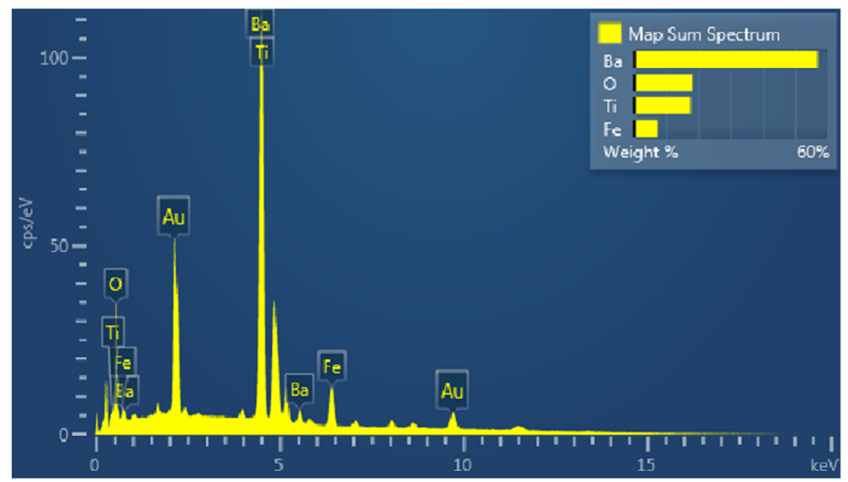

(b)

$\mathrm{Ti} K \alpha 1$

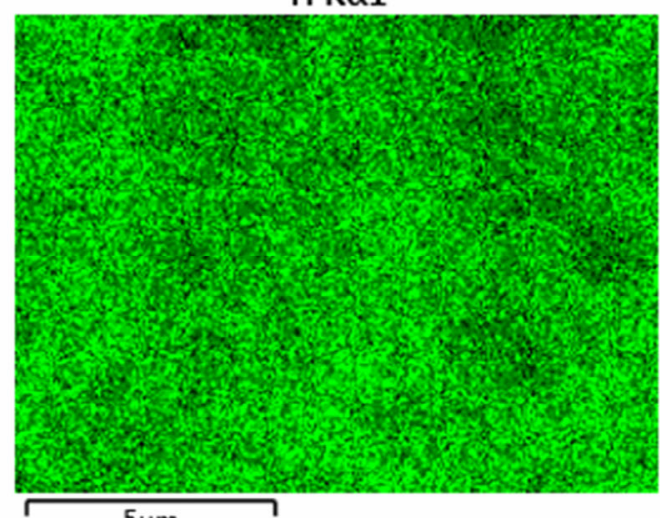

$5 \mu \mathrm{m} \quad$ Fe K $\alpha 1$

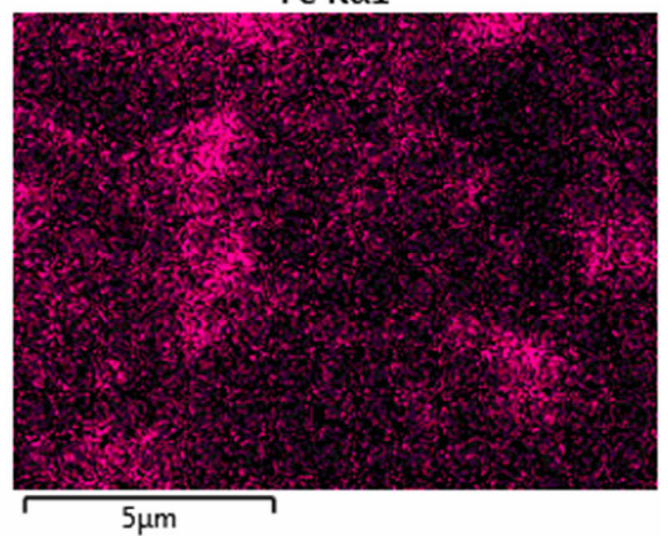

(c)

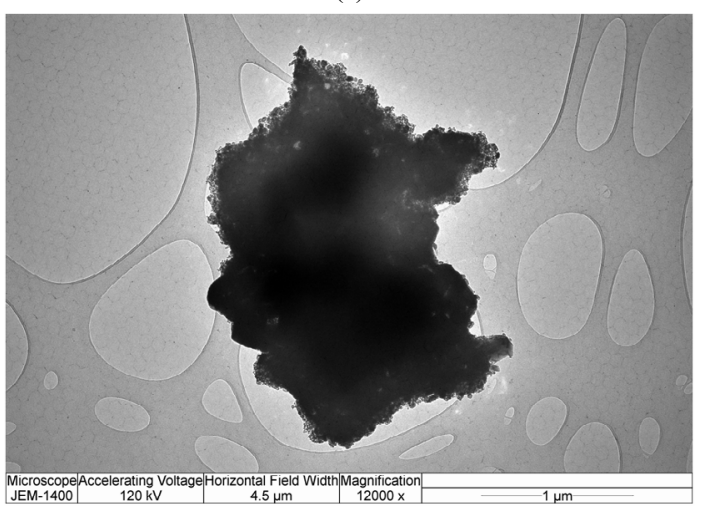

(d)

Fig. 8 (a) SEM; (b) EDS; (c) mapping of elements; (d) TEM for the sample BTF5. 


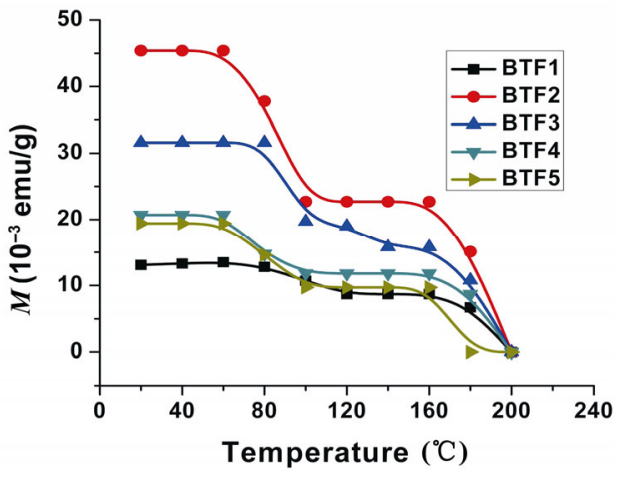

Fig. 9 Dependence of magnetization versus temperature.

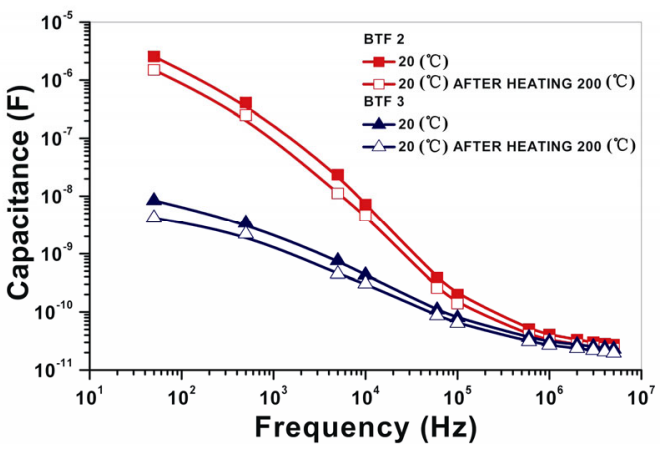

Fig. 10 Capacitance of the samples BTF2 and BTF3 versus frequency.

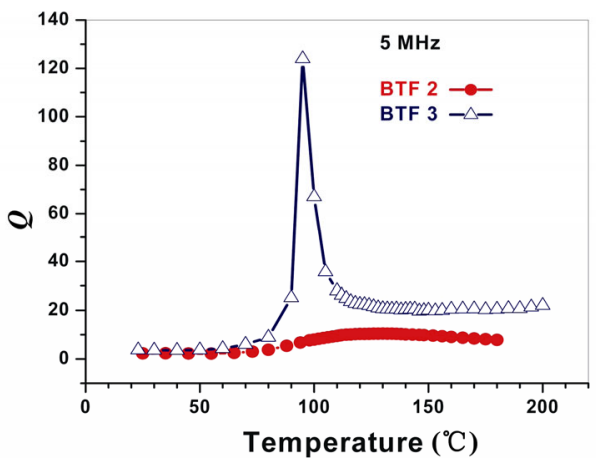

Fig. 11 Changes of $Q$ factor with annealing temperature.

most probably on contact surface between $\mathrm{BaTiO}_{3}$ core and iron oxide shell, drastically reduces temperature of ferroelectric transition [6,42]. The broad hump of $Q$ factor within the BTF2 sample is very similar as it is found by Deka et al. [42] for sample with addition of $\mathrm{Fe}$ in $\mathrm{BaTiO}_{3}$ matrix, due to lower amount of dielectric phase of $\mathrm{BaTiO}_{3}$. However, the sharp pick for the sample BTF3 at $95{ }^{\circ} \mathrm{C}$ is a consequence of higher amount of dielectric phase, over $90 \%$ (Table 1).

\section{Conclusions}

In this paper, the influence of preparation condition on structures and properties of $\mathrm{BaTiO}_{3} / \alpha-\mathrm{Fe}_{2} \mathrm{O}_{3}$ core/shell composite materials were investigated. The changes in phase composition and ratio of observed phases were detected by XRD analyses. The results pointed out that with decrease of $\mathrm{pH}$ value during synthesis, significantly lower amount of iron compounds was formed. However, for samples synthesized at lower $\mathrm{pH}$, purer phase composition was obtained. Raman spectroscopy was performed in order to detect modifications of lattice vibrations with alteration in preparation condition. It confirmed the global mentioned trend in phase alternations detected by XRD and indicated the reduction of $\mathrm{BaTiO}_{3}$ tetragonality in BTF2-BTF5 samples. Changes in morphology were investigated by SEM, TEM, and EDS measurements. The observed results demonstrated almost uniform coating of $\mathrm{BaTiO}_{3}$ powder with synthesized Fe oxides for sample BTF1. Magnetization and electrical measurements indicated some coupling effect between the ferromagnetism and ferroelectricity. Furthermore, the temperatures of ferroelectric and ferromagnetic transition were determined.

\section{Acknowledgements}

This research was performed within the project No. 172057 financed by the Ministry of Education, Science and Technological Development of the Republic of Serbia and NSF CREST (HRD-0833184), NASA (NNX09AV07A) and NSF-PREM1523617 awards.

\section{References}

[1] Hou DL, Zhou ZZ, Ye XJ, et al. Multiferroicity in ion-implanted Fe: $\mathrm{BaTiO}_{3}$ film. Phys Proc 2012, 32: 498-502.

[2] Liu RZ, Zhao YZ, Huang RX, et al. Multiferroic ferrite/perovskite oxide core/shell nanostructures. J Mater Chem 2010, 20: 10665-10670.

[3] Kozielski L, Clemens F. Multiferroics application: magnetic controlled piezoelectric transformer. Process Appl Ceram 2012, 6: 15-20.

[4] Srinivas A, Raja MM, Sivaprahasam D, et al. Enhanced ferroelectricity and magnetoelectricity in $0.75 \mathrm{BaTiO}_{3}$ $0.25 \mathrm{BaFe}_{12} \mathrm{O}_{19}$ by spark plasma sintering. Process Appl Ceram 2013, 7: 29-35.

[5] Ristanović Z, Kalezić-Glišović A, Mitrović N, et al. The influence of mechanical activation and thermal treatment on magnetic properties of the $\mathrm{BaTiO}_{3}-\mathrm{Fe}_{x} \mathrm{O}_{y}$ powder mixture. Process Appl Ceram 2015, 47: 3-14.

[6] $\mathrm{Xu} \mathrm{B}$, Yin $\mathrm{KB}$, Lin $\mathrm{J}$, et al. Room-temperature ferromagnetism and ferroelectricity in $\mathrm{Fe}$-doped $\mathrm{BaTiO}_{3}$. 
Phys Rev B 2009, 79: 134109.

[7] Surowiak Z, Bochenek D. Multiferroic materials for sensors, transducers and memory devices. Arch Acoust 2008, 33: 243-260.

[8] Gao XS, Xue JM, Wang J, et al. Sequential combination of constituent oxides in the synthesis of $\mathrm{Pb}\left(\mathrm{Fe}_{1 / 2} \mathrm{Nb}_{1 / 2}\right) \mathrm{O}_{3}$ by mechanical activation. J Am Ceram Soc 2002, 85: 565-572.

[9] Kim JS, Cheon CI, Jang PW, et al. Ferroelectric and ferromagnetic properties of $0.2 \mathrm{BiFeO}_{3}-0.2 \mathrm{RFeO}_{3}-0.6 \mathrm{ATiO}_{3}$ $(\mathrm{R}=\mathrm{Pr}, \mathrm{Nd}$ and $\mathrm{A}=\mathrm{Ba}, \mathrm{Pb})$ and $0.8 \mathrm{BiFeO}_{3}-0.2 \mathrm{BaTiO}_{3}$.J Eur Ceram Soc 2004, 24: 1551-1555.

[10] Wang J, Neaton JB, Zheng $\mathrm{H}$, et al. Epitaxial $\mathrm{BiFeO}_{3}$ multiferroic thin film heterostructures. Science 2003, 299: 1719-1722.

[11] Hill NA, Filippetti A. Why are there any magnetic ferroelectrics. J Magn Magn Mater 2002, 242-245: 976-979.

[12] Roy S, Majumder SB. Recent advances in multiferroic thin films and composites. J Alloys Compd 2012, 538: 153-159.

[13] Wang Y, Hu JM, Lin YH, et al. Multiferroic magnetoelectric composite nanostructures. NPG Asia Mater 2010, 2: 61-68.

[14] Koo YS, Song KM, Hur N, et al. Strain-induced magnetoelectric coupling in $\mathrm{BaTiO}_{3} / \mathrm{Fe}_{3} \mathrm{O}_{4}$ core/shell nanoparticles. Appl Phys Lett 2009, 94: 032903.

[15] Chaudhuri A, Mandal K. Large magnetoelectric properties in $\mathrm{CoFe}_{2} \mathrm{O}_{4}: \mathrm{BaTiO}_{3}$ core/shell nanocomposites. J Magn Magn Mater 2015, 377: 441-445.

[16] Zhou JP, Lv L, Liu Q, et al. Hydrothermal synthesis and properties of $\mathrm{NiFe}_{2} \mathrm{O}_{4} @ \mathrm{BaTiO}_{3}$ composites with well-matched interface. Sci Technol Adv Mater 2012, 13: 045001.

[17] Corral-Flores V, Bueno-Baques D, Ziolo RF. Synthesis and characterization of novel $\mathrm{CoFe}_{2} \mathrm{O}_{4}-\mathrm{BaTiO}_{3}$ multiferroic core-shell-type nanostructures. Acta Mater 2010, 58: 764-769.

[18] Corral-Flores V, Bueno-Baques D, Carrillo-Flores D, et al. Enhanced magnetoelectric effect in core/shell particulate composites. J Appl Phys 2006, 99: 08J503.

[19] Chaudhuri RG, Paria S. Core/shell nanoparticles: classes, properties, synthesis mechanisms,characterization, and applications. Chem Rev 2012, 112: 2373-2433.

[20] Mančić D, Paunović V, Vijatović M, et al. Electrical characterization and impedance response of lanthanum doped barium titanate ceramics. Sci Sinter 2008, 40: 283-294.

[21] Arlt G, Hennings D, With GD. Dielectric properties of fine-grained barium titanate ceramics. J Appl Phys 1985, 58: $1619-1625$.

[22] Mornet S, Elissalde C, Bidault O, et al. Ferroelectric-based nanocomposites: toward multifunctional materials. Chem Mater 2007, 19: 987-992.

[23] Koo YS, Bonaedy T, Sung KD, et al. Magnetodielectric coupling in core/shell $\mathrm{BaTiO}_{3} / \gamma-\mathrm{Fe}_{2} \mathrm{O}_{3}$ nanoparticles. Appl Phys Lett 2007, 91: 212903.

[24] Singh S, Kumar N, Jha A, et al. Study of magnetic, dielectric and magnetodielectric properties of $\mathrm{BaTiO}_{3} / \mathrm{Fe}_{3} \mathrm{O}_{4}$ core/shell nanocomposite. J Mater Sci: Mater El 2015, 26: $32-36$.
[25] Buscaglia MT, Buscaglia V, Curecheriu L, et al. $\mathrm{Fe}_{2} \mathrm{O}_{3} @ \mathrm{BaTiO}_{3}$ core/shell particles as reactive precursors for the preparation of multifunctional composites containing different magnetic phases. Chem Mater 2010, 22: 4740-4748.

[26] Pavlović VP, Popović D, Krstić J, et al. Influence of mechanical activation on the structure of ultrafine $\mathrm{BaTiO}_{3}$ powders. J Alloys Compd 2009, 486: 633-639.

[27] Frey MH, Payne DA. Grain-size effect on structure and phase transformations for barium titanate. Phys Rev B 1996, 54: 3158-3168.

[28] Pavlović VP, Krstić J, Šćepanović MJ, et al. Structural investigation of mechanically activated nanocrystalline $\mathrm{BaTiO}_{3}$ powders. Ceram Int 2011, 37: 2513-2518.

[29] De Faria DLA, Silva SV, de Oliveira MT. Raman microspectroscopy of some iron oxides and oxyhydroxides. J Raman Spectrosc 1997, 28: 873-878.

[30] Kelm K, Mader W. The symmetry of ordered cubic $\gamma-\mathrm{Fe}_{2} \mathrm{O}_{3}$ investigated by TEM. $J$ Chem Sci 2006, 61: 665-671.

[31] Malina O, Tuček J, Jakubec P, et al. Magnetic ground state of nanosized $\beta-\mathrm{Fe}_{2} \mathrm{O}_{3}$ and its remarkable electronic features. RSC Adv 2015, 5: 49719-49727.

[32] Buscagila V, Buscagila MT. Core/shell heterostructures: from particles sznthesis to bulk dielectric, ferroelectric, and multiferroic composite materials. In Nanoscale Ferroelectrcs and Multiferroics. Alguero M, Gregg JM, Mitoseriu L, Eds. Wiley, 2016: 72-99.

[33] Buscaglia MT, Viviani M, Zhao Z, et al. Synthesis of $\mathrm{BaTiO}_{3}$ core/shell particles and fabrication of dielectric ceramics with local graded structure. Chem Mater 2006, 18: 4002-4010.

[34] Shebanova ON, Lazarov P. Raman spectroscopic study of magnetite $\left(\mathrm{FeFe}_{2} \mathrm{O}_{4}\right)$ : a new assignment for the vibrational spectrum. J Solid State Chem 2003, 174: 424-430.

[35] Durán P, Gutierrez D, Tartaj J, et al. On the formation of an oxycarbonate intermediate phase in the synthesis of $\mathrm{BaTiO}_{3}$ from (Ba,Ti)-polymeric organic precursors. $J$ Eur Ceram Soc 2002, 22: 797-807.

[36] Avakyants LP, Gorelik VS, Zlobina LI, et al. Raman scattering study of $\mathrm{NaNO}_{2}$-infiltrated opal photonic crystals. Inorg Mater 2006, 42: 635-640.

[37] Cho WS, Hamada E. Synthesis of ultrafine $\mathrm{BaTiO}_{3}$ particles from polymeric precursor: their structure and surface property. J Alloys Compd 1998, 266: 118-122.

[38] Naik R, Nazarko JJ, Flattery CS, et al. Temperature dependence of the Raman spectra of polycrystalline $\mathrm{Ba}_{1-x} \mathrm{Si}_{x} \mathrm{TiO}_{3}$. Phys Rev B 2000, 61: 11367-11372.

[39] Pavlovic VP, Nikolic MV, Pavlovic VB, et al. Raman responses in mechanically activated $\mathrm{BaTiO}_{3} . \mathrm{J} \mathrm{Am}$ Ceram Soc 2014, 97: 601-608.

[40] Chen MS, Shen ZX, Tang SH, et al. Stress effect on Raman spectra of Ce-doped $\mathrm{BaTiO}_{3}$ films. J Phys: Condens Matter 2000, 12: 7013-7023.

[41] Park YB, Ruglovsky JL, Atwater HA. Microstructure and properties of single crystal $\mathrm{BaTiO}_{3}$ thin films synthesized by ion implantation-induced layer transfer. Appl Phys Lett 
2004, 85: 455.

[42] Deka B, Ravin S, Perumal A, et al. Ferromagnetism and ferroelectricity in Fe doped $\mathrm{BaTiO}_{3}$. Physica B 2014, 448: 204-206.

[43] Curecheriu L, Postolache P, Buscaglia MT, et al. Novel magnetoelectric ceramic composites by control of the interface reactions in $\mathrm{Fe}_{2} \mathrm{O}_{3} @ \mathrm{BaTiO}_{3}$ core/shell structures. $J$ Appl Phys 2014, 116: 084102.

[44] Mahajan RP, Patankar KK, Kothale MB, et al. Magnetoelectric effect in cobalt ferrite-barium titanate composites and their electrical properties. Pramana-J Phys 2002, 58: 1115-1124.

[45] Curecheriu L, Postolache P, Buscaglia V, et al. $\mathrm{BaTiO}_{3}$-ferrite composites with magnetocapacitance and hard/soft magnetic properties. Phase Transit 2013, 86: 670-680.
Open Access This article is licensed under a Creative Commons Attribution 4.0 International License, which permits use, sharing, adaptation, distribution and reproduction in any medium or format, as long as you give appropriate credit to the original author(s) and the source, provide a link to the Creative Commons licence, and indicate if changes were made.

The images or other third party material in this article are included in the article's Creative Commons licence, unless indicated otherwise in a credit line to the material. If material is not included in the article's Creative Commons licence and your intended use is not permitted by statutory regulation or exceeds the permitted use, you will need to obtain permission directly from the copyright holder.

To view a copy of this licence, visit http://creativecommons.org/licenses/by/4.0/. 